\title{
Oralidad y litigio en América Latina. Principales hallazgos de un estudio empírico ${ }^{1}$
}

\author{
LEONEL GONZÁLEZ ${ }^{2}$
}

leonel.gonzalez@cejamericas.org

MARCO FANDIÑO ${ }^{3}$

marco.fandino@cejamericas.org

GALILEU - REVISTA DE DIREITO E ECONOMIA · e-ISSN 2184-1845

Volume XX - $1^{\text {st }}$ July Julho $-31^{\text {TH }}$ December Dezembro $2019 \cdot$ pp. 61-83

DOI: http://doi.org/10.26619/2184-1845.XX.2.4

Submitted on October $8^{\text {th }}, 2019 \cdot$ Accepted on November 15 $15^{\text {th }}, 2019$

Submetido em 8 de Outubro, 2019 . Aceite a 15 de Novembro, 2019

RESUMEN Desde una perspectiva comparada, en este artículo se analizan algunos de los aspectos más relevantes relacionados con la calidad del funcionamiento de la oralidad en los sistemas penales adversariales en 19 países de América Latina. En base a evidencia empírica, se analiza comparativamente cómo se ha regulado la oralidad y cuáles son las principales audiencias existentes en la práctica; cómo funcionan la oralidad y la litigación y si estas permiten obtener información de mayor calidad y, finalmente, cuál es el nivel de avance del instituto del juicio por jurados.

PALABRAS CLAVE Oralidad, Litigación, Juicio por Jurados, Sistema Penal Acusatorio, Justicia Adversarial

ABSTRACT From a comparative perspective, this article analyzes some of the most relevant aspects related to the quality of the litigation in adversarial criminal systems in 19 Latin American countries. Based on empirical evidence, it is comparatively analyzed how orality has been regulated and what are the main hearings in practice; how orality and litigation work and if these allow obtaining higher quality information and, finally, what is the level of progress of the jury trial institute.

KEYWorDS Orality, Litigation, Trial by Juries, Adversarial Criminal System

\footnotetext{
1 Este trabajo está basado en el estudio "La justicia penal adversarial en América Latina. Hacia la gestión del conflicto y la fortaleza de la ley", CEJA y Fundación KAS, 2018, disponible en: www.cejamericas.org

2 LLM en Derecho Penal y Procesal Penal (Osgoode, Canadá), Director de Capacitación (CEJA).

3 Máster en Gobernanza y Derechos Humanos (UAM, España), Director de Estudios y Proyectos (CEJA).
} 


\section{Introducción}

Este artículo sintetiza los principales hallazgos del informe: "La Justicia Penal Adversarial en América Latina. Hacia la gestión del conflicto y la fortaleza de la ley" (CEJA, 2018), un estudio empírico realizado entre el Centro de Estudios de Justicia de las Américas y la Fundación Konrad Adenauer. El ámbito del estudio fueron 19 países de América Latina, incluyendo varias jurisdicciones en aquellos países federales como Argentina, Brasil y México. El principal objetivo del estudio fue realizar un diagnóstico del estado de situación de la justicia penal adversarial, tras haberse finalizado la instalación del sistema penal acusatorio en casi todos los países hispanohablantes de la región.

Para ello, se identificaron autores y autoras locales que pudiesen hacer un levantamiento de información basado en aspectos cualitativos de vital interés para la investigación como, por ejemplo, la calidad de la litigación oral en la celebración de las audiencias. Dicha información es extraída de entrevistas a operadores del sistema de justicia o a especialistas con un conocimiento profundo sobre estas materias.

En este artículo ofrecemos una visión panorámica del estado de situación de los sistemas procesales penales en los siguientes ámbitos: a) Los diversos tipos de audiencias reguladas, indicando los principales objetivos de las mismas así como anomalías en el uso de las audiencias para fines distintos a los provistos normativamente; b) La calidad de la oralidad, esto es, si la litigación de las partes permite generar información de alta calidad en las audiencias; c) la regulación del juicio por jurado como uno de los elementos centrales en la recuperación de la esencia del modelo de enjuiciamiento adversarial previsto en la mayoría de las constituciones latinoamericanas.

\section{Oralidad, calidad de la litigación y juicio por jurados}

\section{2. a. La estructura procesal del sistema adversarial}

Uno de los ejes rectores en la instalación del sistema adversarial estuvo dado por la sustanciación del proceso a través de audiencias orales, públicas y contradictorias. Particularmente, este modelo reposa en tres etapas procesales principales: la judicialización del caso (formalización de la investigación) para aquellos supuestos en los que el Ministerio Público tome la decisión de iniciar una persecución penal en contra del imputado; el control de la acusación (etapa intermedia) para poner en discusión la labor de investigación que ha hecho el fiscal y decidir si ésta reúne mérito para habilitar un juicio; y el debate oral y público (fase de juicio) para aquellos casos que no hayan podido ser resueltos mediante una salida alternativa y solamente puedan dirimirse mediante la producción de prueba. Aunque esta es la base procesal, 
el modelo adversarial se funda en que todos los planteos de las partes y todas las decisiones jurisdiccionales deben tomarse por regla en el marco de una audiencia.

Si bien la oralidad se saldó legalmente en la etapa de juicio (pues todos los países cuentan con una audiencia), aún subsiste la necesidad de consolidarla en la etapa preliminar en tanto las realidades locales demuestran que, en general, las audiencias previas no están reguladas o funcionan débilmente. En la siguiente tabla se halla la información sobre las audiencias orales reguladas en los códigos procesales penales de la región.

Tabla 2. Audiencias orales reguladas en los Códigos Procesales Penales de América Latina ${ }^{4}$

\begin{tabular}{|c|c|c|c|c|c|}
\hline PAís & $\begin{array}{l}\text { CONTROL DE } \\
\text { DETENCIÓN5 }\end{array}$ & $\begin{array}{l}\text { FORMULACIÓN DE } \\
\text { IMPUTACIÓN }\end{array}$ & $\begin{array}{l}\text { MEDIDAS } \\
\text { CAUTELARES }\end{array}$ & $\begin{array}{l}\text { SALIDAS } \\
\text { ALTERNATIVAS Y } \\
\text { ABREVIADO }\end{array}$ & $\begin{array}{l}\text { ETAPA } \\
\text { INTERMEDIA }\end{array}$ \\
\hline Argentina (Federal) ${ }^{6}$ & Si (72 horas) & $\mathrm{Si}$ & $\mathrm{Si}$ & $\mathrm{Si}$ & Si \\
\hline Argentina (Neuquén) & Si (24 horas) & $\mathrm{Si}$ & $\mathrm{Si}$ & $\mathrm{Si}$ & Si \\
\hline Bolivia & $\mathrm{No}^{7}$ & No & $\mathrm{Si}$ & $\mathrm{Si}$ & No \\
\hline Brasil (Federal) ${ }^{8}$ & \multirow{2}{*}{ Si (24 horas) } & \multirow{2}{*}{ No } & \multirow{2}{*}{ Si } & \multirow{2}{*}{ No } & \multirow{2}{*}{ No } \\
\hline Brasil (Bahía) & & & & & \\
\hline Chile & Si (24 horas) & $\mathrm{Si}$ & $\mathrm{Si}$ & $\mathrm{Si}$ & Si \\
\hline Colombia & Si (36 horas) & $\mathrm{Si}$ & $\mathrm{Si}$ & $\mathrm{Si}$ & Si \\
\hline Costa Rica & No & No & $\mathrm{Si}^{9}$ & No & $\mathrm{Si}$ \\
\hline Cuba & No & No & No & No & No \\
\hline
\end{tabular}

4 En este gráfico se alude a la regulación legal de las audiencias; se hará una nota explicativa en aquéllos casos en los cuales las audiencias se realicen en la práctica judicial sin estar necesariamente reguladas.

5 En esta columna, en los casos que corresponda, entre paréntesis se indicará el plazo máximo que regulan los ordenamientos procesales entre la detención y la realización de la audiencia de control de detención.

6 Se consignan las audiencias reguladas en el CPP sancionado en diciembre de 2014 y vigente desde junio de 2019 en la justicia federal de las provincias de Salta y Jujuy.

7 El artículo 226 del CPP de Bolivia solo prevé que la persona aprehendida por la policía o la fiscalía sea puesta a disposición de la autoridad judicial, en el plazo de veinticuatro horas, para que la misma resuelva, dentro del mismo plazo, sobre la aplicación de alguna medida cautelar o decrete su libertad por falta de indicios. El informe local de Bolivia indica que "no se realiza una audiencia de control de la detención, pero tampoco se hace el control por escrito. Como en la mayoría de los casos se cumplen los plazos, es decir que la policía o fiscalía pone el detenido a disposición del juez en 24 horas, todos los casos pasan directamente a la audiencia de solicitud de medida cautelar. En los casos en los que los plazos no se cumplieron, la defensa plantea un incidente por ilegalidad de la aprehensión - por actividad procesal defectuosa e inobservancia o violación de derechos y garantías (artículo $169 .^{\circ}$ ) - durante la audiencia cautelar, pero considerando que en la mayoría de los casos el juez determina la detención preventiva y entonces la detención se torna legal".

8 En Brasil rige un único Código Procesal Penal tanto para la justicia federal como para los Estados.

9 El informe de Costa Rica indica que "parte de la conquista llevada a cabo a través de la capacitación iniciada en el año 2004 (...) fue hacer conciencia en los jueces, defensores y fiscales sobre la necesidad de hacer real el derecho a ser escuchado antes de tomar una decisión tan delicada como es una prisión preventiva. No fue sino hasta el año 2009, mediante la Ley de Protección de Víctimas, Testigos y demás sujetos intervinientes en el Proceso Penal que se reformó la ley para prever la celebración de una audiencia en los casos en que fuera solicitada una prisión preventiva". Es decir, que se trató de un cambio que surgió desde la práctica. 


\begin{tabular}{|c|c|c|c|c|c|}
\hline PAís & $\begin{array}{l}\text { CONTROL DE } \\
\text { DETENCIÓN5 }\end{array}$ & $\begin{array}{l}\text { FORMULACIÓN DE } \\
\text { IMPUTACIÓN }\end{array}$ & $\begin{array}{l}\text { MEDIDAS } \\
\text { CAUTELARES }\end{array}$ & $\begin{array}{l}\text { SALIDAS } \\
\text { ALTERNATIVAS Y } \\
\text { ABREVIADO }\end{array}$ & $\begin{array}{l}\text { ETAPA } \\
\text { INTERMEDIA }\end{array}$ \\
\hline Ecuador & Si (24 horas) & Si & Si & $S \mathbf{S}^{10}$ & Si \\
\hline El Salvador & No & No"1 & $\mathrm{Si}$ & $\mathrm{Si}$ & $\mathrm{Si}$ \\
\hline Guatemala & Si (24 horas) & $\mathrm{Si}$ & Si & Si & $\mathrm{Si}^{12}$ \\
\hline Honduras & Si $(24 \text { horas })^{13}$ & No & $\mathrm{Si}$ & $\mathrm{Si}$ & $\mathrm{Si}^{14}$ \\
\hline México (Federal) ${ }^{15}$ & \multirow{2}{*}{ Si (48 horas) ${ }^{16}$} & \multirow[b]{2}{*}{$\mathrm{Si}^{17}$} & \multirow[b]{2}{*}{ Si } & \multirow[b]{2}{*}{ Si } & \multirow[b]{2}{*}{ Si } \\
\hline México (Nuevo León) & & & & & \\
\hline Nicaragua & Si $(48 \text { horas) })^{18}$ & $\mathrm{Si}$ & $\mathrm{Si}$ & $\mathrm{Si}$ & $S i^{19}$ \\
\hline
\end{tabular}

10 Con la entrada en vigencia del Código Orgánico Integral Penal, en Ecuador se derogó la suspensión condicional del procedimiento. En este apartado solo aludimos a la regulación del juicio abreviado.

11 En El Salvador, si bien se estipula que el control de detención, formalización y medidas cautelares se discutan en el marco de una audiencia (la "inicial"), aún la lógica del proceso remite a un sistema tradicional mediante el cual la primera audiencia sirve para tomar declaración indagatoria al imputado y tras ello se habilitan los plazos de investigación (de "instrucción" según la terminología del ordenamiento local).

12 La etapa intermedia del proceso penal en Guatemala se subdivide entre la audiencia intermedia (para discutir acerca del hecho por el que el/la fiscal/a formula acusación y, en su caso, dictar el auto de apertura a juicio) y la audiencia de ofrecimiento de prueba (para discutir sobre los medios de prueba que ofrecen las partes y que serán admitidos para el juicio).

$13 \mathrm{Si}$ bien en Honduras está previsto que el/la imputado/a debe ser presentado ante el/la juez/a en un plazo de 24 horas en aquellos casos en los que se encuentre detenido/a, el informe local informa que "una vez que el imputado se encuentra en el Juzgado, se recibe su declaración en una audiencia prevista a dicho efecto. Previo a que se rinda la misma, el juez informa al imputado los hechos que se le imputan en el requerimiento y los derechos que le asisten". Esta dinámica responde a la lógica de la declaración indagatoria del sistema procesal mixto en donde esta etapa es considerada meramente como una instancia formal y de recibimiento de declaración.

14 La etapa intermedia del proceso penal de Honduras consiste en la audiencia preliminar, prevista para la formalización de la acusación, contestación de cargos y el auto de apertura a juicio. La audiencia de preparación del debate (para plantear recusaciones, excepciones o nulidades basadas en hechos nuevos) y la audiencia de proposición de pruebas (para que las partes presenten la lista de medios de prueba indicando los hechos o circunstancias que se pretenden probar con cada uno) se produce en etapa de juicio oral.

15 Aludimos únicamente a la estructura procesal del Código Nacional de Procedimientos Penales, que se encuentra en vigencia tanto en la justicia federal como en todas las Entidades Federativas.

16 En México, "en los casos de detenciones en flagrancia, una vez que la persona detenida es puesta a disposición del Ministerio Público, ya sea por parte de la Policía o de cualquier otra persona, el Ministerio Público cuenta con un plazo de 48 horas para investigar y decidir si pone a la persona detenida a disposición del juez para controlar su detención y resolver sobre su situación jurídica. A dicho plazo de 48 horas se le conoce como "plazo de retención". Si agotado el plazo de retención, el Ministerio Público decide no presentar a la persona detenida ante el juez de control entonces no existe un control judicial de dicha detención. Cabe agregar que el Ministerio Público, durante el plazo de retención, tiene la facultad de poner en libertad a la persona detenida o de imponerle una medida de protección, cuando se trate de delitos que no merezcan prisión preventiva oficiosa y determine que no solicitará la prisión preventiva como medida cautelar, en términos del artículo 140 del CNPP".

17 En México, de forma posterior a la formulación de imputación, el Ministerio Público debe solicitar "la vinculación a proceso" del imputado, lo cual implica discutir sobre los datos de prueba con que cuenta el fiscal para sostener que ha existido un hecho que es delito y que el imputado ha participado en él.

18 En Nicaragua, la discusión sobre el control de detención, formalización (acusación, según la terminología local) y medidas cautelares se produce en el marco de la denominada "audiencia preliminar", regulada entre los artículos 255 a 264 del Código Procesal Penal de Nicaragua.

19 La etapa intermedia del proceso penal en Nicaragua se encuentra desdoblada en dos fases: por un lado, en la audiencia inicial (regulada entre los artículos 265 y 272 del CPP), que tiene como finalidades principales determinar si existe causa para proceder a Juicio e iniciar el procedimiento para el intercambio de las pruebas 


\begin{tabular}{llllll}
\hline PAís & $\begin{array}{l}\text { CONTROL DE } \\
\text { DETENCIÓN5 }\end{array}$ & $\begin{array}{l}\text { FORMULACIÓN DE } \\
\text { IMPUTACIÓN }\end{array}$ & $\begin{array}{l}\text { MEDIDAS } \\
\text { CAUTELARES }\end{array}$ & $\begin{array}{l}\text { SALIDAS } \\
\text { ALTERNATIVAS } \\
\text { ABREVIADO }\end{array}$ & $\begin{array}{l}\text { ETAPA } \\
\text { INTERMEDIA }\end{array}$ \\
\hline Panamá & $\mathrm{Si}(24$ horas) & $\mathrm{Si}$ & $\mathrm{Si}$ & $\mathrm{Si}$ & $\mathrm{Si}$ \\
\hline Paraguay & No & $\mathrm{No}$ & $\mathrm{Si}$ & $\mathrm{Si}$ & $\mathrm{Si}^{20}$ \\
\hline Perú & $\mathrm{No}^{21}$ & $\mathrm{No}$ & $\mathrm{Si}$ & $\mathrm{Si}$ & $\mathrm{Si}$ \\
\hline República Dominicana & $\mathrm{No}^{22}$ & $\mathrm{No}$ & $\mathrm{Si}$ & $\mathrm{Si}$ & $\mathrm{Si}$ \\
\hline Uruguay & $\mathrm{Si}(24$ horas) & $\mathrm{Si}$ & $\mathrm{Si}$ & $\mathrm{Si}$ & $\mathrm{Si}$ \\
\hline Venezuela & $\mathrm{Si}(48$ horas) & $\mathrm{No}$ & $\mathrm{No}$ & $\mathrm{No}$ & $\mathrm{Si}$ \\
\hline Fuen
\end{tabular}

Fuente: Elaboración propia

El diseño de los códigos procesales penales latinoamericanos nos indica que coexisten diversas tendencias en la regulación de la estructura procesal del modelo adversarial. En un ejercicio clasificatorio, podríamos distinguir la existencia de tres tipos distintos de proceso adversarial.

El primero está dado por el llamado proceso adversarial clásico, que consiste en la estipulación de la oralidad como principio general y en un conjunto variado de audiencias para la toma de todas las decisiones jurisdiccionales durante la etapa preliminar. En este modelo están comprendidos los casos de Argentina (tanto a nivel federal - con el CPPN no implementado - como en la provincia de Neuquén), Chile, Ecuador, México, Panamá y Uruguay. En todos estos países se han estipulado audiencias para el control de la legalidad

(es decir, determinar el supuesto fáctico de la acusación). Y, por otro lado, en la audiencia preparatoria de juicio oral (regulada en el artículo 279 del CPP), que se celebra a petición de parte dentro de los cinco días anteriores a la realización del juicio, con el objetivo de discutir sobre la exclusión y acuerdos de prueba.

20 El Código Procesal Penal de Paraguay regula audiencias para la discusión de medidas cautelares, salidas alternas y acusación. Sin embargo, en el informe local se manifiesta que "las audiencias orales propiamente se realizan únicamente en la etapa de juicio. En la preparatoria e intermedia no se implementan".

21 Sin perjuicio de que en Perú no está regulada una audiencia de control de detención, el informe local consigna que a partir de diciembre del 2016 "se ha abierto paso a una suerte de regulación primigenia de esta forma de control, toda vez que se ha concretizado una audiencia donde se va a controlar la legalidad de la detención. Sin embargo, dicho plenario solo operará en un supuesto específico, esto es, en los casos donde exista flagrancia y el fiscal requiera al juez de la Investigación Preparatoria dentro de las doce horas de producida la detención efectiva por la Policía Nacional, la emisión de un mandato de detención judicial hasta por un máximo de siete días, cuando por las circunstancias del caso se desprenda cierta posibilidad de fuga u obstaculización de la averiguación de la verdad, siendo que antes de las 24 horas el juez realizará la audiencia (para) pronunciarse (...) en cuanto a la legalidad de la detención del imputado, sobre el cumplimiento de los derechos al momento de la detención y finalmente sobre la necesidad de dictar la detención judicial".

22 En el informe local se indica que "no existe una audiencia de control de detención. Tal control se lleva a cabo en la audiencia de medidas de coerción si el Ministerio Público decide solicitarla. En la práctica, por lo general, si un imputado es arrestado, el Ministerio Público solicita la medida de coerción. En este caso, sí se contempla un plazo de 48 horas, que también está consagrado en la Constitución, para presentar al imputado ante el juez, sino el Ministerio Público dispone su libertad inmediata." 
de la detención, formulación de la imputación, discusión de medidas cautelares, salidas alternativas y juicio abreviado, y control de la acusación. Es decir, que ante cualquier planteo de las partes se prevé que estos se diriman en el marco de una audiencia.

Un segundo modelo está dado por el proceso adversarial burocratizado, cuyo rasgo distintivo es la supervivencia de elementos característicos de los procesos mixtos o inquisitivos. Si bien algunos códigos, como el de El Salvador, estipulan la realización de audiencias en las fases tempranas del proceso, responden a la lógica del sistema tradicional en tanto mantienen instituciones como la declaración indagatoria como acto procesal inicial o incluso mantienen ese instituto pero solamente en sede fiscal y sin la necesidad de realizar una audiencia para formalizar la imputación, como Costa Rica. La mantención de la lógica tradicional también puede observarse en la regulación de la etapa intermedia. En Guatemala, esta fase se desdobla en dos audiencias fijando la primera para el debate sobre la admisión del caso a juicio y la segunda para la discusión sobre los medios de prueba que las partes pretenden presentar para acreditar sus posiciones. En Honduras, la admisión del caso se da en la audiencia preliminar y la discusión probatoria en la instancia de juicio oral. En esta estructura subyace una visión muy débil sobre la fase intermedia en tanto la litigación sobre la prueba se encuentra fuertemente limitada al producirse de forma posterior a la decisión sobre el sobreseimiento o la apertura a juicio. En cambio, en un sistema adversarial clásico, todas las discusiones sobre la admisibilidad debiesen darse en el marco de una sola audiencia y bajo la comprensión que el debate probatorio es dirimente para sopesar la viabilidad o éxito del caso.

El tercer y último modelo lo constituye el denominado proceso adversarial escriturizado. Es aquél en el cual la mayoría de las decisiones judiciales de la etapa preliminar se adoptan de manera escrita (como en Brasil, Cuba o Costa Rica) o en el que las audiencias se han convertido en representaciones distorsionadas de la oralidad. Una muestra de ello está dada por los casos de Brasil, en donde la audiencia de control de detención (de custodia) gira alrededor de un escrito (auto de prisión en flagrante) que le presenta la policía al juez o Venezuela, en donde el informe local manifiesta que "la realización de audiencias ha pasado a ser la excepción, incluso en la fase de juicio. Es usual la conversación informal el día señalado entre jueces, fiscales y defensores sobre los casos para luego hacer pasar al imputado y/o acusado a firmar las actas. La muestra más evidente la constituye las sentencias condenatorias provenientes en más de un $75 \%$ de admisiones de hecho". 


\section{2.b Calidad del litigio en las audiencias}

En esta sección haremos un análisis acerca de los principales problemas y fortalezas en la dinámica de las audiencias orales que funcionan actualmente en los procesos penales latinoamericanos.

\section{Audiencias de control de detención}

En las audiencias de control de detención se observan dos problemas centrales. Por un lado, un rol muy pasivo del juez en el análisis de las condiciones en las que el imputado fue detenido. Por ejemplo, en Bolivia se informa que "el/la juez/a de instrucción no realiza un control de la duración de la aprehensión de oficio, sino siempre a solicitud de la defensa" y en la provincia argentina de Neuquén se alude que "el/la juez/a no controla de oficio si hubo apremios ilegales en contra del imputado, ni revisa si se le informaron sus derechos". El informe nacional de Chile consignó que "la cifra de detenciones declaradas como ilegales es sostenidamente baja a lo largo de los años, pues en el período observado (2006-2015) estas no superan en ninguno de los años al 1\% del total de audiencias". En cuanto al rol del/de la juez/a, "solo en un $20 \%$ de los casos observados tiene un rol activo en verificar las circunstancias de la detención; el juez pregunta al imputado si conoce y comprende los motivos de su detención en el 53\% de los casos; y en un 31\% de los casos pregunta al imputado por el trato recibido". Un segundo problema está dado por la primacía del expediente escrito o la ausencia de una instancia específica para controlar la detención, como en Brasil, en donde el/la juez/a recibe un escrito de la fiscalía y la discusión de la audiencia gira en torno a éste o en Costa Rica, en donde "el primer contacto que tiene una persona investigada o un imputado con un juez es en la audiencia de medidas cautelares". También se advierten inconvenientes en el cómputo de los plazos, como en Honduras, en donde "suele suceder que el término de la detención se comienza a contar a partir de la hora en que consta la lectura de derechos. Esta situación debe superarse a partir de las disposiciones de la Corte Suprema de Justicia (...) donde establece que la privación de libertad se contabiliza desde el momento en que al imputado se le priva de la misma".

\section{Audiencias de formalización de la investigación}

La audiencia de formalización de la investigación se encuentra regulada en diez sistemas procesales del total de los veintidós analizados y en el plano práctico se advierten dos tipos de problemas. Por un lado, una litigación formal por parte de los intervinientes, representada principalmente en la lectura de escritos o la descripción de los hechos desde la lógica del parte policial. En Chile, "las partes suelen intervenir de manera mecá- 
nica, pues el/la fiscal/a se limita a leer la formalización en la audiencia, sin generar un discurso pues se hace uso de un texto escrito que lee. Esta percepción es confirmada con datos sobre la duración de las audiencias. La audiencia de formalización se redujo de 10 minutos en promedio en el año 2006 a un promedio de 7,9 en el año 2015". En Guatemala, "la formulación de la imputación por parte del fiscal se realiza sin concentrarse en los hechos más importantes (la existencia del delito y probabilidad de participación del sindicado). Cometen la falencia de desarrollar relatos extensos y discuten (incluidos los defensores) las actuaciones del expediente de investigación, por lo que en algunas audiencias persiste la lectura de documentos". En Ecuador se afirmó que hay una "tendencia a que el discurso parta del parte policial". Por otro lado, existe una confusión entre la discusión de los hechos en el marco de la formulación de imputación y en el de la materialidad para las medidas cautelares. Por ejemplo, el informe de Panamá indica que no hay consenso en cuanto a la posibilidad de que, en esta instancia, la defensa debata y argumente sobre el fondo de la imputación. De hecho, desde el plano legal también se han generado este tipo de confusiones. Mientras que en Chile se trata de una facultad autónoma de la fiscalía, en otros países como Uruguay se regula que los jueces y juezas deben resolver si la admiten.

\section{Audiencias de medidas cautelares}

Las audiencias de medidas cautelares tienen aún un conjunto de problemas irresueltos que han sido objeto de discusión en las últimas décadas. El primero está dado por la ausencia de una estructura que defina los momentos para los distintos debates que se dan en ella. Esto se relaciona con un déficit legal, como en Bolivia, en donde el informe local consigna que "el Código Procesal Penal no define la estructura de la audiencia, pues solo establece los requisitos para la imposición de medidas cautelares". Por su lado, en Cuba, "en 1977 se suprimió la audiencia verbal para la imposición de medidas cautelares y se le entregó esta facultad al fiscal (mientras que) en 1994 se eliminó la intervención de los tribunales en esta decisión" es decir que actualmente se realiza por escrito.

Una segunda área se relaciona con un déficit en la calidad de información con la cual se litiga en esta audiencia. De este aspecto dieron cuenta una gran cantidad de informes nacionales. En Bolivia se produce una discusión muy débil del supuesto material en tanto "la exposición del/la fiscal no logra constituir un relato que describa de forma clara el hecho, la calificación legal que le corresponde y la participación que el imputado tuvo en el mismo". En cuanto al presupuesto procesal, agrega que "en gran parte de los casos, el/ la fiscal no ofrece $u$ ofrece muy poca evidencia para fundamentar los riesgos procesales que alega, con lo cual se invierte la carga de la prueba y son los imputados, a través de sus 
abogados, los que tienen que aportar evidencia sobre su arraigo social, familiar o laboral". Además, se informa que los elementos principales que se utilizan para configurar los riesgos procesales dicen relación con la gravedad del delito y la ausencia o existencia de antecedentes policiales o judiciales. De hecho, se señala que "respecto a la evidencia utilizada para definir el arraigo laboral, se observa que tanto jueces como fiscales exigen a la defensa la presentación de documentos que son muy difíciles de conseguir, tales como contratos registrados por una instancia pública (Ministerio de Trabajo)". Un problema adicional en Bolivia está dado por el hecho de que "en un importante porcentaje de casos los/as fiscales no participan en las audiencias, limitándose a enviar el cuaderno de investigaciones y la solicitud de imposición de una medida cautelar". En Chile "la calidad de la información es precaria (...) pues la argumentación de la fiscalía suele limitarse a la lectura del parte policial". Además, "se advierte que no existe un orden rígido en el debate, en el sentido de mantener la ritualidad de comenzar con el supuesto material y luego el procesal". Por otro lado, "el defensor en general no proporciona datos ni presenta una teoría propia, pues se limita a desvirtuar los argumentos de la Fiscalía. El fiscal no argumenta sobre la existencia del hecho en un $40 \%$ de los casos observados; no lo hace sobre la participación del imputado en el hecho en un 50\% de los casos y en un $45 \%$ tampoco lo hace en relación a la necesidad de cautela". En Nicaragua, "para efectos de la imposición de medidas cautelares, la fiscalía sustenta su solicitud de los riesgos procesales sobre la base de la acusación, peligro de evasión, gravedad o magnitud de los hechos, la posible pena a imponer y la naturaleza del delito". Además "existen delitos que por imperio de Ley deben ser tramitados bajo la medida cautelar de prisión preventiva”. En Ecuador hay problemas en la justificación del peligro procesal. La fiscalía "se limita a indicar que la defensa no ha justificado vínculos con la colectividad. Explicación ilegítima en razón de que la Fiscalía es quien tiene la carga de la prueba". En la provincia argentina de Neuquén, "a los fines de discutir los riesgos procesales, principalmente los vinculados con la falta de arraigo, las fiscalías suelen contar con poca información sobre la situación personal del/a imputado/a y no cuentan con un servicio dentro del Ministerio Público Fiscal que se encargue de esta búsqueda". Es decir que podemos concluir que aún se trata de una audiencia que gira alrededor de los elementos tradicionales vinculados a la imputación (tipo de delito y pena en expectativa) y no se ha logrado torcer el debate hacia elementos concretos relativos a la situación personal del imputado.

Un tercer y último problema se vincula con la ausencia de fijación de plazos y mecanismos de supervisión de las medidas cautelares. En Bolivia se consignó que esto no ocurre en la mayoría de las audiencias mientras que Chile carece de una institución dedicada a dar seguimiento al cumplimiento de las medidas cautelares y "el comportamiento habi- 
tual de los defensores es no solicitar al juez la fijación de un plazo judicial en consideración de los antecedentes concretos de la causa. Y, en los casos en que se produce el debate, este es promovido en su mayoría de oficio por el juez (52\%) versus un $32 \%$ de los casos en que se promueve por la defensa". En el estado mexicano de Nuevo León se informó que "en 5 de 6 casos, el/la juez/a impuso medidas cautelares sin especificar su duración; solo se limitó a expresar que aquellas tendrían vigencia 'durante el procedimiento'". Sin perjuicio de ello se han dado experiencias interesantes en relación a estos dos últimos problemas. En Nicaragua, "El Código Procesal Penal contiene las normativas pertinentes para dar el adecuado seguimiento y control a las medidas cautelares impuestas a toda persona sometida a proceso penal. En el país se han creado oficinas de apoyo a la labor judicial que permiten obtener información fidedigna sobre el cumplimiento de las medidas cautelares, por ejemplo, la Oficina de Control de Procesados, donde diariamente se recibe a las y los acusados, quienes llegan a firmar una ficha de control de presentación periódica, según la frecuencia señalada por el juez en la resolución". En Panamá, "una práctica a destacar es que en la provincia de Colón los fiscales desde la Sección de Atención Primaria en la cual se prepara la carpeta para las labores de litigación que posteriormente realizará la Sección de Decisión y Litigación Temprana envían comisión a la Dirección de Investigación Judicial para que se verifique si el imputado tiene residencia fija o no, si labora, si tiene familia, vínculos con la comunidad (todos los temas de arraigo), cuál es su historia médica, entre otros. Esta información la utilizan para seleccionar de inicio la medida cautelar que estiman idónea".

\section{Audiencias de salidas alternativas}

En relación a las audiencias de salidas alternativas (suspensión condicional del proceso y acuerdos reparatorios) se observa un tema central: no existe una tendencia marcada en la región en cuanto a la necesidad de que el juez asuma un rol activo en la solución del conflicto primario. Por ejemplo, en Costa Rica se señaló que "los jueces penales no hacen un gran esfuerzo como en otras materias para lograr soluciones alternativas al juicio. Su rol se puede resumir en un agente de control de legalidad y cumplimiento de los requisitos" y en Honduras que "el juez únicamente confirma que los requisitos formales concurran para autorizar la salida alterna. En relación con los términos del acuerdo, el juez no ejerce mayor control, sólo verifica que el imputado conozca los alcances de la medida alterna y que esté de acuerdo con los términos de la reparación del daño". Sin embargo, cabe mencionar los casos de la provincia argentina de Neuquén, en donde como buena práctica se resalta que "el/la juez/a siempre controla que el imputado preste su conformidad y le explica la finalidad y los efectos del beneficio, así como las consecuencias que acarrea no 
cumplir con las reglas de conducta establecidas" y Chile, en donde en las audiencias de suspensión condicional del proceso "en un $80 \%$ de los casos el juez pregunta al imputado si entiende las condiciones que le son impuestas; y, por otro lado, en el 67\% de los casos el juez señala expresamente al imputado que al aceptar la suspensión condicional está renunciando a su derecho al juicio oral. En cuanto a los acuerdos reparatorios, el juez explica sus consecuencias al imputado en un $72 \%$ de los casos y en un $63 \%$ de las ocasiones le pregunta si entiende el contenido y alcances del acuerdo. Por otro lado, en un $80 \%$ de los casos, el juez le da la palabra a la víctima antes de que acepte el acuerdo; y en un $77 \%$ lo toma en consideración al momento de aprobarlo. En estos casos, "el tipo de contraprestación más usual es el pago de una suma de dinero representando un 58\% y disculpas públicas en un $23 \%$ ".

\section{Audiencia de etapa intermedia}

La audiencia de etapa intermedia no se ha consolidado como una instancia central en la generación de acuerdos o depuración de la prueba de manera preparatoria al juicio oral. Esta afirmación se apoya principalmente en la baja intensidad en la exclusión probatoria durante esta audiencia.

En Chile, "existe cierto temor en dejar fuera cierta prueba del juicio oral. (...) El rol del defensor tampoco parece ser muy activo, ya que la defensa solicita la exclusión de alguno de los medios de prueba ofrecidos por el fiscal en el 35\% de los casos; y la defensa ofrece prueba propia en solo un $40 \%$ de los casos". En cuanto a los tiempos de duración de esta audiencia, cabe resaltar que "en el año 2006 duraba en promedio 37,5 minutos, mientras que en el año 2014 esa cifra se redujo a 16,4 minutos en promedio". En El Salvador, "no todos los jueces de instrucción discuten la pertinencia de la prueba. Si la defensa no se opone a la introducción de prueba, el juez la admite". En Ecuador, "los debates son formales y superficiales en todos los temas. (...) En los acuerdos probatorios normalmente solo se hacen referencias formales, simplemente se menciona que no hay acuerdos y no existe un intento real de negociación". En República Dominicana, "el desconocimiento de las técnicas de litigación la afecta al nivel de profundidad con el que se llevan a cabo las discusiones, pero sobre todo el rol del juzgador cuando se vuelve demasiado pasivo debiendo resultar todo lo contrario". En Colombia, en "la audiencia preparatoria, en la que se han introducido numerosos pasos que la han hecho repetitiva y poco ágil, (...) existen confusiones entre los conceptos de pertinencia, conducencia y utilidad de las pruebas, que generan discursos reiterativos que no aportan en la acotación del debate probatorio". Esto tiene un impacto en la dinámica del juicio oral, en tanto "al no existir una adecuada depuración de las pruebas, pueden llevarse hasta decenas de testigos de los cuales solo unos 
resultan útiles para lo que se pretende demostrar. De otra parte, tampoco ha sido afortunada la forma en la que se introducen las pruebas al juicio, pues se confunden los testimonios con la lectura de informes y entrevistas que no permiten garantizar el principio de contradicción". En la provincia argentina de Neuquén, "si bien esta audiencia debería utilizarse como la última instancia para llegar a acuerdos entre las partes (de suspensión del proceso a prueba o de procedimiento abreviado), ya que la ley así lo establece, luego de esta audiencia si las partes llegan a salidas alternas, los jueces aceptan estos acuerdos". En Guatemala "en la audiencia intermedia, una de las quejas recurrentes de los jueces es que el fiscal desconoce el caso, por lo que es común la mala práctica de leer la acusación en la audiencia. Este problema es derivado del modelo de gestión de las fiscalías, en donde el fiscal que llevó a cabo la investigación no entrega el caso a tiempo al fiscal de litigios que participará en la audiencia intermedia. En la audiencia ofrecimiento de prueba, se han identificado dos debilidades: que los jueces no generan la discusión sobre los medios de prueba por parte de la fiscalía y la defensa; y que regularmente, los sujetos procesales describen a detalle el objeto de la declaración de testigos y peritos, lo cual constituye un antecedente negativo para el tribunal de sentencia, por lo que es común la afirmación "la prueba llega contaminada" al juicio". En el informe estadual de México se informa que "esta audiencia pierde relevancia dado que el debate se adelanta durante la audiencia inicial por la figura de vinculación a proceso. Existe una iniciativa de reforma para eliminar la vinculación a proceso de la audiencia inicial, lo que de proceder permitiría fortalecer la etapa intermedia".

En otros países se ha llegado a eliminar esta audiencia o analizar su exclusión. En Bolivia, esta audiencia estuvo sujeta a diversos cambios. Si bien el CPP aprobado en 1999 previó la realización de una audiencia preparatoria de juicio, lo cierto es que éstas no se realizaban con frecuencia. Esto llevó a que en el 2010 se introduzcan cambios al ordenamiento normativo para detallar la dinámica específica que dicha audiencia debía seguir. Sin perjuicio de ello, el informe nacional indica que "debido a los problemas administrativos que dificultaron sobre manera la instalación de dichas audiencias, en octubre de 2014, la ley de descongestionamiento y efectivización del sistema penal modificó nuevamente el CPP y obligó al juez instructor a remitir la acusación al juez o tribunal de sentencia en el plazo máximo de 24 horas". Es decir, que se eliminó la regulación de la audiencia de etapa intermedia y se reemplazó por una remisión directa por escrito. Por su lado, en Costa Rica, "desde la jerarquía del Poder Judicial han sido anunciados proyectos para proponer reformas legislativas que eliminen esta audiencia, de forma tal que los casos pasen directo desde la redacción de la acusación hacia el debate o juicio oral (...). Se dice en Costa Rica que la audiencia preliminar, lejos de ser una fase 
estratégica para el funcionamiento del sistema, se volvió en un mero trámite (...) Ello ha obligado a los jueces de juicio a tener que atender incidentes de exclusión de prueba ilícita, actividades procesales defectuosas y hasta casos que no debieron haber llegado a esa etapa".

\section{Audiencia de juicio oral}

Por último, si bien el juicio oral existe en la región hace décadas, lo cierto es que actualmente presenta dos problemas centrales. Por un lado, se advierte aún un rol activo del juez en la realización de preguntas a los testigos. En Bolivia, "el rol del/la juez/a durante la audiencia de juicio no es totalmente pasivo. Los operadores entrevistados coinciden en afirmar que regularmente los jueces formulan preguntas a los testigos, para aclarar las dudas que tienen". En Brasil, sin perjuicio de que en el 2008 se reformó el texto del ordenamiento procesal para incorporar la técnica del examen y contra examen de la prueba, en la actualidad los jueces y juezas tienen un rol muy activo en la realización de preguntas a los/as testigos, lo cual en varios casos supera la profundidad con la cual los interrogan los y las litigantes. En Cuba, a partir de una guía metodológica para la realización de juicios orales emitida por el Tribunal Supremo Popular, se intentaron corregir ciertos vicios en la dinámica del juicio oral. En la actualidad, tal como afirma el informe local, "al comienzo del juicio el secretario da lectura a un resumen de los hechos que son objeto de la acusación, que ha sido previamente elaborado por el juez ponente de la causa, de tal suerte que si las partes prescinden de la lectura de sus escritos de calificación, como sigue ocurriendo en la actualidad, los presentes tengan al menos una referencia del contenido de la acusación". Una vez realizado el interrogatorio de testigos y peritos, los tribunales tienen libertad para el interrogatorio, facultad que por lo general ejercen, para lograr la mayor certeza sobre el controvertido. Tienen también la posibilidad de incorporar determinados medios probatorios, consistente en todos aquellos que consideren necesarios para la comprobación de cualquiera de los hechos que hayan sido objeto de los escritos de las partes, cuando no han sido suficientemente esclarecidos, a criterio del juzgador".

Por otro lado, se observa una baja calidad en la litigación durante la audiencia de juicio. Esto se desprende de la realidad de un conjunto de países. En Chile, "existe la percepción de que los interrogatorios son meros ejercicios retóricos, más bien mecánicos y que los contrainterrogatorios son inconsistentes. (...) Un dato que resulta importante destacar es el aumento en las sentencias absolutorias. En el año 2006, el porcentaje de sentencias condenatorias alcanzó el 81\% del total, mientras que en el año 2015 alcanzó el $65,3 \%$ de las sentencias de tribunales de juicio oral". En Ecuador, "el contra examen (...) 
se hace de manera ineficaz; la falta de técnica para sacar a relucir debilidades hace que lo más común es que sea una extensión del interrogatorio. Las objeciones son inutilizadas". En Costa Rica, "no se permite a las partes, por ejemplo, hacer un alegato inicial. Cuando en algunos lugares se inició esa práctica, magistrados de la jerarquía en sus giras por el país decían que esa práctica era ilegal, porque en Costa Rica la norma dice que el fiscal debe leer la acusación. Ello motivó a que se abandonara esa práctica. De modo que un tribunal de juicio inicia un debate habiendo escuchado solamente la lectura de la acusación, sin dar a la defensa la posibilidad de proponer una visión distinta al tribunal". En Honduras, "la prueba testifical sigue siendo una de las más propuestas por las partes, por lo cual resulta preciso resaltar la necesidad de mejorar las técnicas de interrogatorio y contrainterrogatorio; sobre todo frente a la regulación procesal del país que prohíbe la formulación de preguntas capciosas o sugestivas en los mismos. (...) Esta necesidad de reforzar la técnica de interrogatorio y contra interrogatorio de las partes, se refleja precisamente en que para superar los vacíos de información (debido a la falta de una técnica adecuada), los tribunales intervienen activamente formulando preguntas que consideren oportunas y que no se han realizado por las partes o se han realizado de forma incorrecta". Sin embargo, cabe resaltar la experiencia de la provincia argentina de Neuquén, en donde "por regla general, se advierte que las partes durante las audiencias de juicio tienen una estrategia sobre el caso" y que "durante toda la audiencia, el/ la juez/a asume un rol pasivo y nunca introducen preguntas". La implementación del juicio por jurados ha aumentado la calidad del litigio y permitido que el lenguaje de los litigantes se simplifique.

\section{2.c. La regulación del juicio por jurados}

En el apartado anterior nos referimos a las problemáticas que se presentan alrededor de los juicios orales en la región. En esta sección nos focalizaremos en una de las modalidades posibles para la sustanciación del juicio: mediante un tribunal integrado por jurados populares. En nuestra opinión, esta dinámica constituye uno de los mecanismos más eficaces para ampliar la participación de la ciudadanía en la justicia penal y democratizar el funcionamiento de los sistemas judiciales.

En la siguiente tabla se presenta información relativa al modo en que se encuentra regulado el juicio por jurados en los ordenamientos procesales penales de la región, en particular, en cuanto al tipo de delitos en los que intervienen y la cantidad de integrantes que forman parte del jurado. 
Tabla 3. Situación del juicio por jurados en América Latina

\begin{tabular}{|c|c|c|c|}
\hline PAís & $\begin{array}{l}\text { FUNCIONAMIENTO } \\
\text { DE JUICIO POR } \\
\text { JURADOS }\end{array}$ & TIPOS DE DELITOS EN LOS QUE INTERVIENE & $\begin{array}{l}\text { CANTIDAD DE } \\
\text { INTEGRANTES DEL } \\
\text { JURADO }{ }^{23}\end{array}$ \\
\hline Argentina (Federal) & $\mathrm{No}^{24}$ & - & - \\
\hline Argentina (Neuquén) & Si & $\begin{array}{l}\text { Casos con pena superior a los } 15 \text { años y delitos } \\
\text { contra la integridad sexual o que tengan como } \\
\text { resultado la muerte o lesiones gravísimas }\end{array}$ & 12 \\
\hline Bolivia & No & - & - \\
\hline Brasil (Federal) & $\mathrm{Si}$ & Delitos dolosos contra la vida & 7 \\
\hline \multicolumn{4}{|l|}{ Brasil (Bahía) } \\
\hline Chile & No & - & - \\
\hline Colombia & No & - & - \\
\hline Costa Rica & No & - & - \\
\hline Cuba & $\mathrm{Si}$ & Todos $^{25}$ & 2 \\
\hline Ecuador & No & - & - \\
\hline El Salvador & Si & $\begin{array}{l}\text { Lesiones, lesiones graves y muy graves, lesiones } \\
\text { agravadas, relativos a la autonomía personal y } \\
\text { daños y daños agravados }\end{array}$ & 5 \\
\hline Guatemala & No & - & - \\
\hline Honduras & No & - & - \\
\hline México (Federal) & No & - & - \\
\hline México (Nuevo León) & No & - & - \\
\hline Nicaragua & Si & $\begin{array}{l}\text { Lesiones graves, lesiones gravísimas y hurto } \\
\text { agravado. }\end{array}$ & 6 \\
\hline
\end{tabular}

23 En esta columna se consigna el número de jurados titulares que intervienen en el juicio.

$24 \mathrm{El}$ artículo 249 del nuevo CPP prevé la integración de un tribunal por jurados cuyas definiciones específicas quedan delegadas a una ley especial: "La ley de juicio por jurados determinará la composición, integración, constitución, sustanciación y deliberación del juicio en el que participe un tribunal de jurados".

25 En Cuba, el autor local informa que "la proporción en cuanto a la integración de los tribunales depende del nivel jurisdiccional y de otras condiciones de organización. Los casos de menor complejidad que se conocen en los municipios, de sanciones hasta un año de privación de libertad, el tribunal se integra por un juez profesional y dos jueces legos. En el nivel provincial y en el Supremo para un grupo considerable de casos, el tribunal se integra por cinco jueces, de los cuales 3 son profesionales y dos legos. Pero hay casos en que el tribunal puede estar integrado por 3 jueces". Cabe precisar que en Cuba "se utiliza la categoría de "jurado" para identificar a los ciudadanos miembros del jurado de corte anglosajón, que emiten un juicio binario sobre culpabilidad, mientras que los ciudadanos que integran el tribunal escabinado tienen la categoría de jueces, en igualdad de condiciones que los jueces profesionales". 


\begin{tabular}{|c|c|c|c|}
\hline PAís & $\begin{array}{l}\text { FUNCIONAMIENTO } \\
\text { DE JUICIO POR } \\
\text { JURADOS }\end{array}$ & TIPOS DE DELITOS EN LOS QUE INTERVIENE & $\begin{array}{l}\text { CANTIDAD DE } \\
\text { INTEGRANTES DEL } \\
\text { JURADO }^{23}\end{array}$ \\
\hline Panamá & Si & $\begin{array}{l}\text { 1. Homicidio doloso que no sea producto de } \\
\text { delitos de terrorismo, secuestro, extorsión, } \\
\text { asociación ilícita, pandillerismo, narcotráfico o } \\
\text { blanqueo de capitales. } \\
\text { 2. Aborto provocado por medios dolosos, } \\
\text { cuando, por consecuencia de este o de los } \\
\text { medios usados para provocarlo, sobreviene la } \\
\text { muerte de la mujer. } \\
\text { 3. Que impliquen un peligro común y los delitos } \\
\text { contra la salud pública cuando, por consecuencia } \\
\text { de ellos, sobreviene la muerte de alguien, con } \\
\text { excepción de los causados por imprudencia, } \\
\text { negligencia o impericia en el ejercicio de una } \\
\text { profesión u oficio. }\end{array}$ & 7 \\
\hline Paraguay & No & - & - \\
\hline Perú & No & - & - \\
\hline $\begin{array}{l}\text { República } \\
\text { Dominicana }\end{array}$ & No & - & - \\
\hline Uruguay & No & - & - \\
\hline Venezuela & No & - & - \\
\hline
\end{tabular}

Fuente: Elaboración propia

El juzgamiento por jurados populares en el proceso penal ha estado en el centro del diseño de la justicia criminal en casi todas las constituciones políticas latinoamericanas desde comienzos del siglo XIX. En muchas de ellas aún continúa regulado pero no se ha vuelto una realidad, como los casos de Argentina (cuya última reforma constitucional, en 1994, ratificó los tres artículos en los que el instituto está previsto), Colombia (los jurados de conciencia están regulados a nivel constitucional mediante el artículo 116 que dispone "los particulares pueden ser investidos transitoriamente de la función de administrar justicia en la condición de jurados en las causas criminales, conciliadores o en la de árbitros habilitados por las partes para proferir fallos en derecho o en equidad, en los términos que determine la ley") y Uruguay. En Chile funcionó, de manera interrumpida, el juicio por jurados para los juicios de imprenta entre 1813 y 1925 . Mediante un breve reglamento sobre libertad de imprenta, se estipuló al jurado como una protección de la libertad de prensa en la época. En México se encuentra expresamente regulado en el artículo 20 de su Constitución del año 1917 como una garantía en los juicios penales. En otros países se ha eliminado, como en Venezuela (el modelo clásico se eliminó en el 2001 y en el 2012 el de escabinos) y Bolivia, en donde el informe local reporta que "el CPP aprobado en 1999 preveía la realización de juicios orales con jueces ciudadanos en el marco del tribunal escabino (dos jueces técnicos 
y tres ciudadanos) para los delitos de acción pública, sancionados con pena privativa de libertad cuyo máximo legal sea mayor a cuatro años. Luego de algunos años, se evidenciaron problemas de gestión que afectaron los procesos de constitución de los tribunales de sentencia, lo cual provocó una elevada congestión judicial que perjudicó sobremanera el inicio y la prosecución de las audiencias de juicio. Por estas razones, en octubre de 2014, la Ley de descongestionamiento y Efectivización del sistema procesal penal suprimió la institución de los jueces ciudadanos". En Nicaragua, frente a la dificultad que se presentó en los últimos años en la convocatoria de jurados ciudadanos, el informe describe que "se ha emprendido una labor de publicidad sobre la responsabilidad ciudadana de impartir justicia, iniciando un programa radial desde hace siete años - denominado una hora con la Justicia, éste se transmite una vez por semana, a este acuden Jueces, abogados litigantes y facilitadores judiciales".

\section{Propuestas para el fortalecimiento de la oralidad y el litigio}

Sin lugar a dudas, la oralidad ha sido uno de los elementos protagónicos en los procesos de reforma a la justicia penal en América Latina. Para iniciar este apartado se podrían mencionar decenas de consideraciones, interpretaciones y análisis que han surgido en base a este emblemático principio de los nuevos sistemas adversariales. Para salirnos de las referencias más conocidas por el público optaremos por iniciar el análisis haciendo mención a una de las cualidades de la oralidad que no siempre ha sido tan destacada. Nos referimos a la vinculación entre oralidad y la idea del juicio.

Dice Binder (2014, p.29) que "cuando se habla de "oralidad" en realidad lo que se quiere transmitir es que todo ciudadano tiene derecho a que no se imponga una pena sin un juicio previo, y juicio no es cualquier trámite sino la estructura (conjunto de formas vinculadas a los actos, sujetos, tiempo, espacio, coerción y caso) que sostiene la imparcialidad, la contradicción y la publicidad". En consecuencia, la idea de juicio como "elemento central del proceso" no sólo se ha invisibilizado en los sistemas de enjuiciamiento inquisitivo sino también en los recientes sistemas adversariales. Por lo tanto, "cuando hablamos de oralidad como uno de los valores de la reforma procesal penal nos referimos a este ideal de juicio previo, en el que se despliegan una serie de herramientas o principios colaterales como la inmediación, publicidad, contradicción y la concentración".

Como extraemos de la reflexión de Binder, la oralidad condensa un ideal de justicia que tiene como contraposición más evidente el trámite inquisitivo en donde la idea de juicio se difumina entre mecánicas actuaciones de carácter secreto y escrito. Esta vinculación de oralidad con la institución del juicio detrás de la cual subyacen un conjunto de efectos 
(como los mencionados) es la cristalización de la concepción de la oralidad como un principio político de las reformas al proceso penal. La finalidad de este objetivo político es desterrar el modelo de juzgamiento inquisitivo caracterizado por la escrituración como forma de juzgamiento de la cual nuevamente se desprenden otras consecuencias como la delegación de funciones jurisdiccionales, la opacidad de las actuaciones judiciales y la íntima convicción del juzgador como criterio valorativo.

Siguiendo nuevamente a Binder (2012), la otra gran dimensión de la oralidad es que nos da la posibilidad de situar a la audiencia como el espacio ideal para que se produzca la pacificación del conflicto. A diferencia del trámite inquisitivo, en donde la participación del imputado y la víctima era marginal, en el sistema adversarial se produce una escenificación del conflicto en la audiencia oral lo que permite que se exteriorice el conflicto y se produzca un debate y deliberación entre los diversos actores allí representados. En esta pacificación del conflicto se destaca la importancia de la ritualidad bien entendida en el sentido de que esa escenificación transmita un mensaje que impacte en los destinatarios en el nivel social.

Como veremos más adelante, uno de los aspectos que es necesario revitalizar en la justicia penal contemporánea es el ideal restaurador y de reparación a través de las vías composicionales de solución de conflictos. La oralidad será la única herramienta que nos permita obtener resultados positivos en este importante desafío.

A continuación, realizaremos un breve análisis de qué aspectos de la oralidad no están teniendo el desarrollo deseado en el funcionamiento actual de los sistemas de justicia penal.

\section{El rescate de la garantía del hecho}

Hemos observado que en muchos de los nuevos sistemas de justicia penal latinoamericanos, la audiencia de formalización de la investigación se ha convertido en una instancia bastante formal en la cual la fiscalía comunica al imputado/a en presencia de su defensor/a y el/la juez/a cuáles son los hechos por los que será investigado. Este momento se convierte en un hito procesal ya que desencadena el cómputo de algunos plazos como, por ejemplo, la duración de la etapa de investigación criminal. Además, en muchos casos esta audiencia se fusiona con otras como la solicitud de alguna medida cautelar sobre el/la imputado/a o la solicitud de alguna salida alternativa al juicio oral.

Se ha comprobado que en varios países existe poca calidad en la información del hecho a formalizar. Esto puede ser debido a dos factores. En primer lugar, ocurre que en el relato de la fiscalía suele existir bastante preeminencia de la información proveniente del parte policial. Esto es problemático ya que supone que la descripción de hechos realizada por el/ la fiscal/a puede estar sesgada y por lo tanto va a afectar con posterioridad todo el trabajo realizado en el proceso penal. En segundo lugar, los hechos descritos en la formalización 
no siempre tienen el nivel de claridad y detalle necesario. Solemos hablar de la necesidad de que los hechos contenidos en la formalización sean autosuficientes y al menos sean capaces de contestar a las siguientes preguntas:¿Quién?¿Cuándo? ¿Dónde? ¿Qué? Y ¿Cómo?

La audiencia, por lo tanto, debe ser el espacio idóneo para poder mejorar y rectificar esta información proveniente de la fiscalía cuando no reúna el estándar adecuado para la formalización de los hechos a investigar. El rol de la defensa será crucial para poder advertir la necesidad de que los hechos se puedan detallar, profundizar o rectificar. La importancia estratégica de la labor de la defensa en esta audiencia viene determinada por el principio de congruencia que limitará la acusación fiscal a los hechos que inicialmente fueron formalizados. El/la juez/a de garantía, por su parte, deberá intervenir en el debate y corroborar si el detalle de los hechos se ha realizado de forma adecuada incluso cuando la defensa no haya controvertido la información (Rua y González, 2018).

Si la audiencia de formalización se convierte en un ritual para comunicar una información al/a la investigado/a, sin ningún tipo de posibilidad de intervención o de modificación en la descripción del hecho, pierde sentido en su papel de favorecer un mejor intercambio de información.

La formalización de la investigación es concebida como un derecho del/de la imputado/a a la que Binder se ha referido como garantía del hecho. Desde esa perspectiva, será necesario advertir del problema que en muchos casos esta formalización venga acompañada de forma inmediata de una solicitud de salida alternativa o de medida cautelar. En estos casos, es posible que el derecho a conocer de forma anticipada cuáles son los hechos sobre los que se está siendo investigado requiera que tengamos un tiempo razonable para asimilar los hechos y analizar estrategias de defensa antes de ser requerido por el Ministerio Público a participar en nuevas actuaciones procesales.

En el último tiempo, en algunos países como Chile, se han planteado algunos debates como la hipótesis de que la formalización de una investigación supone un perjuicio importante para el/la imputado/a, suponiendo una afectación del principio de presunción de inocencia por la realización de juicios paralelos por la opinión pública (Ried, 2017). En ese sentido, es importante recordar que existen varias situaciones procesales en las que las audiencias orales y públicas se realizan con la participación de un/a imputado/a en calidad de presunto inocente sobre el cuál se realizan una serie de acusaciones, en algunos casos solicitudes muy graves como la privación preventiva de libertad a la espera de juicio. Todas estas actuaciones, se realizan de forma pública con la finalidad de que la comunidad en su conjunto pueda tener conocimiento de cómo se resuelven y pacifican los conflictos ante la justicia estatal. Por lo tanto, sin perjuicio de que pueda existir el riesgo de que la imagen o el prestigio del/de la imputado/a se debiliten por estos comportamientos indebidos de 
los medios de comunicación pensamos que esto no justifica la supresión de la publicidad en esta etapa procesal. Por el contrario, deben reivindicarse otras vías que no atenten contra las audiencias públicas y que no supongan volver a concepciones opacas y secretas de la investigación criminal. Pareciese mucho más prudente realizar un trabajo persuasivo y colaborativo de educación a los medios de comunicación acerca de cuáles son las características del sistema de justicia penal que no siempre se ha realizado.

\section{Las audiencias de acuerdos}

La mayoría de países de la región regula audiencias orales para la formalización de acuerdos entre las partes, ya sean suspensiones condicionales del procedimiento o acuerdos reparatorios. El fundamento de estas audiencias suele estar centrado en que el/la juez/a acredita la concurrencia de los requisitos procesales necesarios para la procedencia de estos acuerdos.

Hemos observado que en la mayoría de casos las negociaciones se han producido fuera de la audiencia entre las partes, ya sea entre la fiscalía y el/la defensor/a o directamente entre la víctima y el/la imputado/a, como suele requerirse para el caso de los acuerdos reparatorios. Por lo tanto, como los acuerdos suelen estar conversados de forma previa, las audiencias de acuerdos suelen tener poca duración y pocas veces se desvían de la verificación de los requisitos legales.

Para evitar esa lógica, las audiencias de acuerdos son un espacio privilegiado para discutir las causas reales del conflicto entre las partes y sobre todo, generar diversas alternativas que coadyuven a su solución. Es muy frecuente que a la hora de imponerse una condición al imputado estas suelen formularse de forma excesivamente general o no vinculada al conflicto original o a la resocialización del/de la imputado/a. Si insertamos en la audiencia de acuerdos la lógica de gestión del conflicto, podemos dirigir el debate de, por ejemplo, la suspensión condicional hacia la imposición de una condición que pueda ayudas a reducir el nivel de conflictividad entre las partes e, incluso, a insertarnos en un paradigma restaurador como veremos más adelante.

La labor judicial en las audiencias de acuerdos muchas veces ha quedado diluida por la errónea creencia de que el juez en un sistema adversarial debe ser pasivo y no entrometerse en la litigación de las partes. Por el contrario, el juez o la jueza en la etapa de investigación sí que tiene un rol mucho más activo no sólo en el sentido de exigirle información a las partes, sino también de poder promover que las partes exploren diversas opciones como una salida alternativa. Obviamente, no nos referimos aquí a un/a juez/a que apruebe acuerdos no autorizados por las partes, sino por el contrario un/a juez/a que da la posibilidad a las partes de que exploren y conversen sobre esas alternativas que la legislación procesal ofrece. 
Por otro lado, consideramos que el/la juez/a no debiese ingresar a analizar en cada caso concreto el mérito o la proporcionalidad del acuerdo, ya que la lógica del sistema adversarial confía en que cada una de las partes gestiona su caso en base a sus intereses y la fortaleza de su caso mientras que la autoridad judicial debe resguardar en todo momento su imparcialidad. Solamente en aquellos casos excesivamente desproporcionales o en los que pueda presumirse que existe sometimiento o abuso de una parte sobre la otra, la autoridad judicial debería intervenir (Rua y González, 2017).

\section{Oralidad y medidas cautelares}

En la actualidad, podemos comprobar que en muchos países de la región las audiencias de medidas cautelares no se realizan bajo un debate en profundidad acerca del supuesto material y procesal que fundamenta la posibilidad de imponer una medida cautelar.

Independientemente de que la prisión preventiva ha tenido un rebrote debido a la implementación de la prisión preventiva oficiosa en determinados delitos que ha sucedido en algunos países como México o la restricción de las medidas cautelares alternativas en casos de reincidentes y delitos contra la propiedad así como la aparición de riesgos procesales abstractos en las agendas cortas anti delincuencia de Chile (Fandiño et. al, 2018), es necesario destacar a la oralidad como herramienta para promover un debate de mayor calidad en base a la configuración de los requisitos para imponer una medida cautelar.

Todavía vemos como los y las fiscales solicitan medidas cautelares muy intensas como la prisión preventiva aludiendo a la gravedad del delito o al monto de pena en expectativa. Si bien esta forma de proceder no se corresponde con la forma adecuada de solicitar una medida cautelar, también es grave comprobar como la defensa no suele hacer una contra argumentación ante esta forma de proceder y que el juez no dirige el debate hacia la necesaria focalización del debate en la configuración de los supuestos material y procesal.

En una audiencia de medida cautelar, el/la juez/a de garantía, en su rol de interpelación a las partes para exigirles información como corresponde en la etapa de investigación, debe solicitar a la fiscalía que proceda a la explicación de qué los hechos alegados están tipificados y que existe alguno de los riesgos procesales que la legislación estipula.

Finalmente, otro desafío que debe fortalecerse es la instalación de Servicios de Antelación al Juicio (SAJ) u Oficinas de Medidas Alternativas y Sustitutivas (OMAS) para que un organismo de estas características pueda proveer información objetiva acerca de la situación económica, familiar y laboral del imputado para que el debate de medidas cautelares se produzca sobre la base de información de mayor calidad. 


\section{La oralidad en la etapa intermedia}

Uno de los elementos que garantiza el funcionamiento adecuado del proceso penal es la preservación de la audiencia de juicio oral como un espacio para pacificar sólo los conflictos más graves que el Ministerio Público decida elevar por criterios de política de persecución penal. Como dice Binder, (1993, pág. 231) "muchas de las grandes decisiones de política procesal que le dan carácter al proceso penal pasan por ésta fase intermedia y por el modo concreto como se controla el resultado de la instrucción". De esta forma, esta etapa procesal aparece como la última oportunidad antes del juicio para alcanzar acuerdos entre las partes, para controlar la acusación del fiscal o para preparar la audiencia del juicio oral.

Como se ha explicado (González, 2018) podríamos mencionar tres grandes objetivos asociados a la audiencia de etapa intermedia: A) Mejorar la eficiencia en el sistema de justicia a través de la posibilidad de alcanzar acuerdos entre las partes; b) Controlar la calidad de la información en el proceso y c) Realizar un debate relacionado con admisibilidad y exclusión probatoria.

Hemos analizado varias limitaciones en el funcionamiento de la oralidad en esta etapa procesal. En primer lugar, existen varios países en los cuales todavía no existe regulación específica de audiencias para este momento procesal como Bolivia o en donde los objetivos de esta etapa se encuentran diseminados en dos audiencias como en Guatemala y Honduras. Producto de lo anterior se percibe como en algunos países esta etapa todavía no es vista como un momento central del proceso.

Otro de los déficits en esta audiencia lo encontramos en la participación de los jueces y juezas y su capacidad para dirigir el debate fomentando el contradictorio entre las partes y una mayor calidad de la información. Debiese profundizarse en las técnicas de audiencia para poder generar debates de mayor calidad en esta etapa procesal. Por ejemplo, es frecuente todavía que los debates relacionados con admisibilidad y exclusión probatoria sean bastante formales y no se realice el trabajo de filtrar medios probatorios de baja calidad. En este sentido, creemos que se vuelve necesario rediscutir la teoría probatoria que subyace a la regulación de la etapa intermedia e identificar que el sistema adversarial nos interpela a la construcción de estándares de admisibilidad que sean filtros muy estrictos para la discusión probatoria. En concreto, se impone repensar el criterio de relevancia o pertinencia como aquél que constituye el eje central alrededor del cual debiesen producirse en primer lugar los debates sobre la admisibilidad de la prueba. De hecho, los sistemas adversariales de larga tradición como el canadiense los denomina como el "corazón del sistema de admisión".

Si profundizamos al respecto en los problemas de la prueba pericial, vemos como en países con más de una década de sistema adversarial como Chile todavía persisten pro- 
blemas como el bajo control de la idoneidad del perito, la existencia de un debate de muy baja calidad en torno a la admisibilidad o el poco respaldo de las Cortes de Apelaciones a las decisiones de exclusión probatoria en primera instancia (Duce, 2018).

Existe una gran necesidad de replantear la capacitación a los operadores del sistema de justicia con la finalidad de que se robustezca la audiencia de etapa intermedia, mejorando la calidad de los debates probatorios. Una gran responsabilidad la encontramos en el juez de garantía quien en su rol de gate-keeper debe intensificar el contradictorio entre las partes para que se produzca un debate de mayor intensidad.

Por otro lado, con la finalidad de que la lógica adversarial permita obtener mejores resultados en la calidad del sistema, también se requiere que la Defensa formule una Teoría del Caso propia y que esta se manifieste en la proposición de prueba de descargo para que no se encuentre supeditada a la estrategia y medios probatorios de la Fiscalía. Estos aspectos están condicionados a una serie de necesidades presupuestarias y de fortalecimiento institucional previo en el caso de los defensores públicos.

\section{BIBLIOGRAFÍA}

Binder, A. (1993). Introducción al Derecho Procesal Penal. AD-HOC. Buenos Aires. Argentina.

Binder, A. (2012). La implementación de la nueva justicia penal adversarial. AD-HOC. Buenos Aires. Argentina.

Binder, A. (2014). Elogio de la audiencia oral y otros ensayos. Consejo de la Judicatura del Estado de Nuevo León. México.

Duce, M. (2018). Una aproximación empírica al uso y prácticas de la prueba pericial en el proceso penal chileno a la luz de su impacto en los errores del sistema. Revista Política Criminal, Vol. 113, N. ${ }^{\circ}$ 25. Art. 2, pp. 42-103. 2018

Fandiño, M., Rua, G., Moreno, L. y Fibla, G. (2018). Desafíos de la Reforma Procesal Penal en Chile: Análisis retrospectivo a más de una década. Centro de Estudios de Justicia de las Américas.

Fuchs, M.C., Fandiño, M. y González, L. (2018). La Justicia Penal Adversarial en América Latina. Hacia la gestión del conflicto y la fortaleza de la ley. Centro de Estudios de Justicia de las Américas y Fundación Konrad Adenauer.

González L. (2018). Debates y horizontes de la justicia penal adversarial. Pendiente de publicación.

Ried, I. (2017). La formalización de la investigación como ejercicio de una carga procesal estratégica del Ministerio Público en el proceso penal. Revista de la Justicia Penal, N. ${ }^{\circ}$ 7, págs. 87 y ss.

Rua, G. y González, L. (2018). El rol del juez en un sistema adversarial: Fundamentos y técnicas de conducción de audiencias. En Revista Sistemas Judiciales, Revista N. ${ }^{\circ} 21$, Buenos Aires. 